\title{
The transcriptome of the novel dinoflagellate Oxyrrhis marina (Alveolata: Dinophyceae): response to salinity examined by 454 sequencing
}

\author{
Chris D Lowe*, Luciane V Mello, Najma Samatar, Laura E Martin, David JS Montagnes and Phillip C Watts
}

\begin{abstract}
Background: The heterotrophic dinoflagellate Oxyrrhis marina is increasingly studied in experimental, ecological and evolutionary contexts. Its basal phylogenetic position within the dinoflagellates make $O$. marina useful for understanding the origin of numerous unusual features of the dinoflagellate lineage; its broad distribution has lent O. marina to the study of protist biogeography; and nutritive flexibility and eurytopy have made it a common lab rat for the investigation of physiological responses of marine heterotrophic flagellates. Nevertheless, genome-scale resources for $\mathrm{O}$. marina are scarce. Here we present a 454-based transcriptome survey for this organism. In addition, we assess sequence read abundance, as a proxy for gene expression, in response to salinity, an environmental factor potentially important in determining 0 . marina spatial distributions.
\end{abstract}

Results: Sequencing generated $\sim 57$ Mbp of data which assembled into 7, 398 contigs. Approximately $24 \%$ of contigs were nominally identified by BLAST. A further clustering of contigs (at $\geq 90 \%$ identity) revealed 164 transcript variant clusters, the largest of which (Phosphoribosylaminoimidazole-succinocarboxamide synthase) was composed of 28 variants displaying predominately synonymous variation. In a genomic context, a sample of 5 different genes were demonstrated to occur as tandem repeats, separated by short ( 200-340 bp) inter-genic regions. For HSP90 several intergenic variants were detected suggesting a potentially complex genomic arrangement. In response to salinity, analysis of 454 read abundance highlighted 9 and 20 genes over or under expressed at 50 PSU, respectively. However, 454 read abundance and subsequent qPCR validation did not correlate well - suggesting that measures of gene expression via ad hoc analysis of sequence read abundance require careful interpretation.

Conclusion: Here we indicate that tandem gene arrangements and the occurrence of multiple transcribed gene variants are common and indicate potentially complex genomic arrangements in O. marina. Comparison of the reported data set with existing $O$. marina and other dinoflagellates ESTs indicates little sequence overlap likely as a result of the relatively limited extent of genome scale sequence data currently available for the dinoflagellates. This is one of the first 454-based transcriptome surveys of an ancestral dinoflagellate taxon and will undoubtedly prove useful for future comparative studies aimed at reconstructing the origin of novel features of the dinoflagellates.

\section{Background}

Oxyrrhis marina is a basal dinoflagellate taxon that has been extensively studied in both experimental and ecological contexts $[1,2]$ and increasingly represents a target for studies of dinoflagellate evolution [3]. Oxyrrhis marina appears to have diverged early in the evolutionary

\footnotetext{
* Correspondence: clowe@liv.ac.uk Department of Evolution, Ecology, and Behaviour, Institute of Integrative Biology, University of Liverpool, Biosciences Building, Crown Street, Liverpool, L69 7ZB, UK
} (69) $72 B$, UK

branch leading to the dinoflagellate lineage, close to when the dinoflagellates diverged from the apicomplexans [4-6] and thus occupies a novel position within the alveolates (i.e. the ciliates, dinoflagellates, and apicomplexans). The alveolate lineages have each evolved a variety of unusual molecular and genomic features, the development of which has remained unclear in many cases [7]. The phylogenetic position of O. marina, as an intermediate lineage between the dinoflagellates and the apicomplexans, and the recognition that it possesses 
further unusual cytological and genetic features, make it a significant target for the study of evolutionary patterns and genome organisation within the alveolates [3,7-10].

Despite increasing scientific interest in O. marina, genetic and genomic data for this taxon remain relatively scarce (though see [8]). In part, this is because comparative genomic approaches are limited by the relatively large phylogenetic distances separating O. marina from other genetic/genomic-model protists (e.g. [4,5]). More generally, dinoflagellate genomes remain poorlycharacterised due to several genomic characteristics. For example, dinoflagellates typically possess large genomes $[7,11,12]$ that contain numerous genes arranged in repetitive tandem-arrays [13]; further, they have potentially complex transcriptomes composed of multiple transcript variants for many genes [14]. The occurrence of such traits in O. marina remains only partially characterised: the genome appears to be large [15], and a number of genes occur as multiple transcribed variants [16], but whether these genes are present as tandem-arrays has not been demonstrated.

While full genome sequences remain out of reach, next generation sequencing platforms nonetheless provide an efficient strategy to characterise transcriptomes, which can then be used to (1) quantify genomic features such as novel gene transcripts, alternative splicing, and levels of gene expression; and (2) uncover the molecular basis of adaptive traits in ecological model-organisms that lack reference genomes [17,18]. Thus, high throughput transcriptome sequencing represents a common starting point for large scale sequencing projects for a broad taxonomic range of organisms [18-20]. Indeed, several EST and transcriptome sequence datasets now exist for dinoflagellate species (e.g. [21,22], including an EST dataset for one strain of O. marina [8]. For O. marina, many components of its biology are well-characterised, and it is commonly employed as a model to parameterise ecological processes and trophic interactions (e.g. [23]). Additionally, as a result of its broad distribution and abundance in intertidal environments, O. marina is a useful model of the evolutionary and biogeographic processes that determine the distributions of free-living protists [24]. The wide distribution of $O$. marina is undoubtedly associated with an ability to tolerate a range of environments, notably variation in salinity, temperature, and $\mathrm{pH}$ [25]. Beneath this general pattern, however, is evidence for intra-specific variation in physiological tolerances; for example O. marina isolates display differing tolerances to environmental salinity, which potentially correlate with their occurrence in open water compared with intertidal habitats [26]. Crucially, the molecular basis of differences in physiological tolerances, and hence the mechanisms by which physiological adaptation potentially drives biogeographic patterns, are unknown. Identifying genes that respond to key parameters such as salinity stress represents the first step towards indentifying the basis of physiological differences between strains.

In this paper, we present the first 454-based transcriptome sequence data for O. marina, with the aim of (1) highlighting the occurrence of genomic features such as extensive gene transcript variants, tandemly-arrayed genes, and a gene complement that make it an important target for understanding genome evolution within the dinoflagellates. Moreover, (2) we assess the use of 454 read abundance to determine variation in gene expression in response to salinity stress, and thus we examine the potential molecular basis of salinity tolerance in this eurytopic flagellate. In doing so we provide a substantial dataset that increases the publically available DNA sequence resources for this highly unusual dinoflagellate species.

\section{Methods}

\section{Cell culturing}

To provide RNA for cDNA synthesis and subsequent 454 sequencing, monoclonal cultures of the O. marina isolate 44_PLY01 (source: Plymouth harbour, UK, $50.3632 \mathrm{~N},-4.139 \mathrm{~W}$; see [24]) were established in triplicate with media adjusted to 30 and 50 PSU (practical salinity units). Cultures were grown in modified Droop's S69 axenic growth medium [25] (see [27] for details) and were treated with gentamycin $\left(50 \mu \mathrm{g} \mathrm{ml}^{-1}\right)$ and penicillin/streptomycin solution $\left(100 \mu \mathrm{g} \mathrm{ml}^{-1}\right)$ to limit bacterial growth; absence of bacteria and fungi was confirmed by culturing small volumes of $O$. marina cultures in L1p, L1m, and L1pm test media (media recipes provided by The Provasoli-Guillard National Center for Culture of Marine Phytoplankton, Bigelow Laboratory, Maine, USA) and by visual inspection of DAPI stained culture aliquots using a UV-equipped inverted microscope. Cultures were maintained in the dark at $18^{\circ} \mathrm{C}$ and serially transferred to ensure exponential growth. Specific growth rate $\left(\mu, \mathrm{d}^{-1}\right)$ was calculated from daily estimates of cell density over 5 days (cell densities were estimated by counting $1 \mathrm{ml}$ subsamples using a Sedgewick-Rafter chamber). Cultures were maintained at 30 and 50 PSU for $>10$ generations and were harvested when $1 \mathrm{~L}$ flasks contained $\sim 3.5 \times 10^{7}$ cells.

\section{RNA extraction and CDNA synthesis}

Cells harvested from triplicate cultures were combined, and total RNA was extracted using an RNeasy extraction kit (Qiagen) following the manufacturer's standard protocol. RNA quantity and integrity was assessed using an Agilent Bioanalyser PicoRNA assay (Agilent technologies). cDNA template for sequencing was generated using the standard SMART cDNA synthesis protocol 
(Clontech). First strand cDNA was synthesised using Superscript II reverse transcriptase from $\sim 0.75 \mu \mathrm{g}$ total RNA. Sufficient template for sequencing $(\sim 5 \mu \mathrm{g})$ was generated by long-range PCR; briefly, cDNA was amplified in $90 \mu \mathrm{l}$ PCR containing $1.5 \mu \mathrm{l}$ first strand $\mathrm{cDNA}$ as template, $20 \mathrm{mM}$ dNTPs, $12 \mu \mathrm{M}$ SMART oligo, $50 \mathrm{U}$ Advantage 2 Taq polymerase (Clontech), and the manufacturer's standard PCR buffer; thermal cycling conditions were: $95^{\circ} \mathrm{C}$ for $1 \mathrm{~min}$, followed by 18 cycles of $\left[95^{\circ}\right.$ C $15 \mathrm{~s}, 65^{\circ} \mathrm{C} 30 \mathrm{~s}, 68^{\circ} \mathrm{C} 6 \mathrm{~min}$ ]. Amplified DNA was purified using a standard column-based protocol (Qiagen).

\section{4 sequencing and sequence assembly}

Library construction and pyrosequencing was completed by the Centre for Genomic Research (CGR, http://www. liv.ac.uk/cgr/), University of Liverpool, UK on a 454 GS FLX system (Roche). Libraries created from 30 and 50 PSU salinity treatments were multiplex identified (MIDtagged) and then pooled for sequencing using $0.5 \times$ GS454flx sequencing run. Sequencing reads were quality trimmed and adaptor sequences removed prior to assembly. Contig assembly was performed using Newbler (release 1.1.03.24, Roche), with overlap settings of 35 bp and 99\% identity and default values for the remaining parameters. The overall assembly was performed using the combined sequence data for both salinity treatments, and differentially-expressed genes were identified subsequent to annotation.

\section{BLAST identity searches and sequence annotation}

Sequence contigs were annotated using a priority BLAST search strategy [28]. Briefly, O. marina contigs were compared sequentially against the following databases: Uniprot (release 15.0), NCBI Nr (release 172.0), Pfam (release 24.0), and Smart (version 4.1); identity searches were conducted using BLASTX (for Uniprot, Pfam, Smart) and megaBLAST (BLASTN - for NCBI $\mathrm{Nr}$ ) implementations of the standalone BLAST program.
Initial BLAST parameters were word size 30 (BLASTN), 3 (BLASTX) and an e-value cut-off of $1 \mathrm{e}^{-10}$. After each search the contigs that were not identified at the selected e-value cut-off were queried against the subsequent database (see Table 1). This priority BLAST procedure was repeated for the remaining unidentified contigs at a less-stringent e-value cut-off $\left(1 \mathrm{e}^{-5}\right)$. Finally, contigs identified by BLAST (i.e. those identified at an e-value of $1 \mathrm{e}^{-5}$ or better) were submitted to blast2GO [29] for GO category assignment [30].

Two additional BLASTN searches (using parameters specified above) were conducted between the O. marina RNAseq dataset reported here, an existing genbank $O$. marina EST dataset, and the dinoflagellate EST genbank collection. The degree of similarity between $O$. marina datasets was further explored based on a CAP3 [31] assembly of the combined datasets (see following section).

\section{Analysis of expressed gene variants}

The occurrence of gene variants/clusters was explored based on a CAP3 assembly [31] of 454 contigs; thus potential clusters/variants were identified as groups of contigs sharing $\geq 90 \%$ similarity. For each of the largest clusters indentified in this way, contributing contigs were aligned using Seqman (DNAstar Inc, USA) and obvious errors (e.g. homopolymer length variations) or mis-alignments edited manually. For CAP3 contigs that were identifiable and contained open reading frames > 200bp in length, dN/dS ratios were calculated using KaKs calculator [32]. A further assembly was performed, which included the O. marina CCMP1788 EST dataset. Prior to assembly the CCMP1788 EST data were screened for redundancy ( $\geq 99.5 \%$ identity, $50 \mathrm{bp}$ minimum overlap), which reduced the data from 18, 024 sequences to 11,024 . Subsequently, the 454 RNAseq and EST datasets were assembled at $\geq 90 \%$. Transcripts identified as shared between the datasets were subjected

Table 1 BLAST annotation summary

\begin{tabular}{|c|c|c|c|c|}
\hline Database & e-value $\left(1 e^{-10}\right)$ & $\%$ contigs ID'd & e-value $\left(1 \mathrm{e}^{-5}\right)$ & $\%$ contigs ID'd \\
\hline \multicolumn{5}{|c|}{ All contigs $(n=6,497)$} \\
\hline Uniprot & 655 & 8.9 & 139 & 1.9 \\
\hline $\mathrm{Nr}$ & 434 & 5.9 & 61 & 0.8 \\
\hline Pfam & 118 & 1.6 & 343 & 4.7 \\
\hline Smart & 8 & 0.1 & 61 & 0.8 \\
\hline All databases & 1,215 & 16.5 & 604 & 8.2 \\
\hline \multicolumn{5}{|c|}{ Large contigs $(n=901)$} \\
\hline Uniprot & 322 & 35.7 & 79 & 8.8 \\
\hline $\mathrm{Nr}$ & 71 & 7.9 & 130 & 14.4 \\
\hline Pfam & 58 & 6.4 & 117 & 13.0 \\
\hline Smart & 15 & 1.7 & 9 & 1.0 \\
\hline All databases & 466 & 61.7 & 335 & 37.2 \\
\hline
\end{tabular}


to BLASTX searches against the Genbank non-redundant protein database to infer identity.

\section{Tandem gene PCR and cloning}

For 5 candidates the occurrence of a tandem gene organisation was assayed by PCR. Outward orientated primers were designed within $100 \mathrm{bp}$ of the $3^{\prime}$ and $5^{\prime}$ ends of contigs. PCRs using Phusion polymerase (NEB, Cambridge) were conducted using genomic DNA as template and 3.0 pmol of each primer. In all cases PCR amplicon identity was confirmed by capillary sequencing using Bigdye v3.1 chemistry on an AB3130xl genetic analyser. In 4 of 5 cases, tandem spacer regions generated a mixed sequencing signal indicating the presence of multiple amplicons. For 2 candidates (alpha tubulin and HSP90), PCR products were cloned using the cloneJET blunt end ligation kit (Fermentas) and JM109 competent cells (Promega). For each gene, 24 transformants were sequenced in forward and reverse orientations.

\section{Differential transcript abundance}

The relative abundances of sequence reads from the 2 RNAseq datasets were used to quantify the pattern of gene expression in O. marina exposed to 30 and 50 PSU. The representation of sequence reads from 30 and 50 PSU libraries for each 454 contig was normalised for total library size (i.e. the total number of reads contributing to the assembly), and statistically significant differences in relative abundance between salinity treatments were assessed using the pairwise Audic and Claverie, Fisher exact and Chi-squared tests implemented in the software package IDEG6 [33]. Statistical significance was taken at $\alpha \leq 0.05$, following Bonferroni correction implemented by the IDEG6 software.

Gene expression predictions from sequence read abundances were validated by quantitative PCR (qPCR). PCR primers were designed against 16 contigs with a range of read abundances and 3 nominal control/housekeeping genes. Template for qPCR assays was the same as that used for 454 sequencing. Assays were performed following the manufacturers protocol in $15 \mu \mathrm{l}$ reactions, containing 2x PowerSYBR green (Ambion, Inc, CA) and 3 pmol forward and reverse primer. Target and control primer efficiencies were estimated based on serial dilutions of cDNA template. All PCRs were performed in triplicate on an AB7500 quantitative PCR system. Relative normalised expression metrics were calculated based on $\Delta \Delta C T$ [34]. Consistency of control gene expression was assessed based on pairwise $\Delta \Delta C T$ comparisons between actin, alpha-tubulin, and beta-tubulin. 454 target read abundances were normalised to control gene abundance to allow direct comparison between 454 and qPCR expression metrics.

\section{Results}

\section{Sequence output and assembly statistics}

Sequencing generated 299, 081 raw reads (totalling 57.2 $\mathrm{Mbp}$ ) from the transcriptome of $O$. marina isolate 44PLY_01; following trimming to remove poor-quality and adaptor sequence, 238, 240 reads (median length 228 bp) were available for assembly. 194, 644 reads could be assembled, generating 7, 398 contigs, leaving 30, 869 singletons and 12, 727 reads that were removed as outliers. Median contig length and the mean read number per contig were $226 \mathrm{bp}$ and 25.5 , respectively. 2, 221 contigs were composed of 10 or more reads (10 2, 114 reads) and varied in length from 97-1, $938 \mathrm{bp}$ 901 contigs were greater than 500 bp long (between 4 and 1, 617 reads per contig; Figure 1). Short contigs (< 200bp) were typically represented by relatively small numbers of reads (median $=3$ ). However, a small number of short contigs $(n=49)$ were highly represented in the sequence output (between 203 and 1, 909 reads per contig). Sequence reads are available via the NCBI sequence read archive (SRA accession SRA035395.1). Contig assemblies are included with this manuscript as Additional file 1, and summaries of the longest and most abundant contigs are included as Tables S1 and S2, respectively, in Additional file 2.

\section{Sequence Annotation}

Based on BLASTX and BLASTN identity searches against Uniprot, NCBI Nr, Pfam, and SMART databases we identified $16.5 \%$ of the O. marina contigs at the more stringent e-value cut-off $\left(1 \mathrm{e}^{-10}\right)$. A subsequent reduction in stringency $\left(1 \mathrm{e}^{-5}\right)$ allowed a further $8 \%$ of contigs to be assigned a putative function (thus, $76 \%$ of the $O$. marina contigs could not be identified, Table 1). Notably, 98\% of the large ( $>500 \mathrm{bp}$ ) and all of the contigs greater than 1,500 bp in length were identified by BLAST searches (Table 1, Figure 1), thus the relatively low annotation rate of the dataset stems from an inability to identify relatively short contigs (Figure 1, discussion). The overall degree of similarity between the O. marina RNAseq data presented here, an existing EST data set for O. marina (CCMP1788), and ESTs for the dinoflagellates as a whole was examined by further BLAST identity searches between these 3 datasets. Based on an e value of $1 \mathrm{e}^{-10}$ and $>80 \%$ similarity the numbers of shared sequences are provided in Figure 2; O. marina data sets shared 1410 contigs/ESTs ( 15\%), and 495 contigs/ESTs were common to all three datasets.

\section{Transcriptome coverage, representation, and gene variants}

To examine the relative coverage of transcripts by 454 sequencing, the length and aligned position of contigs 


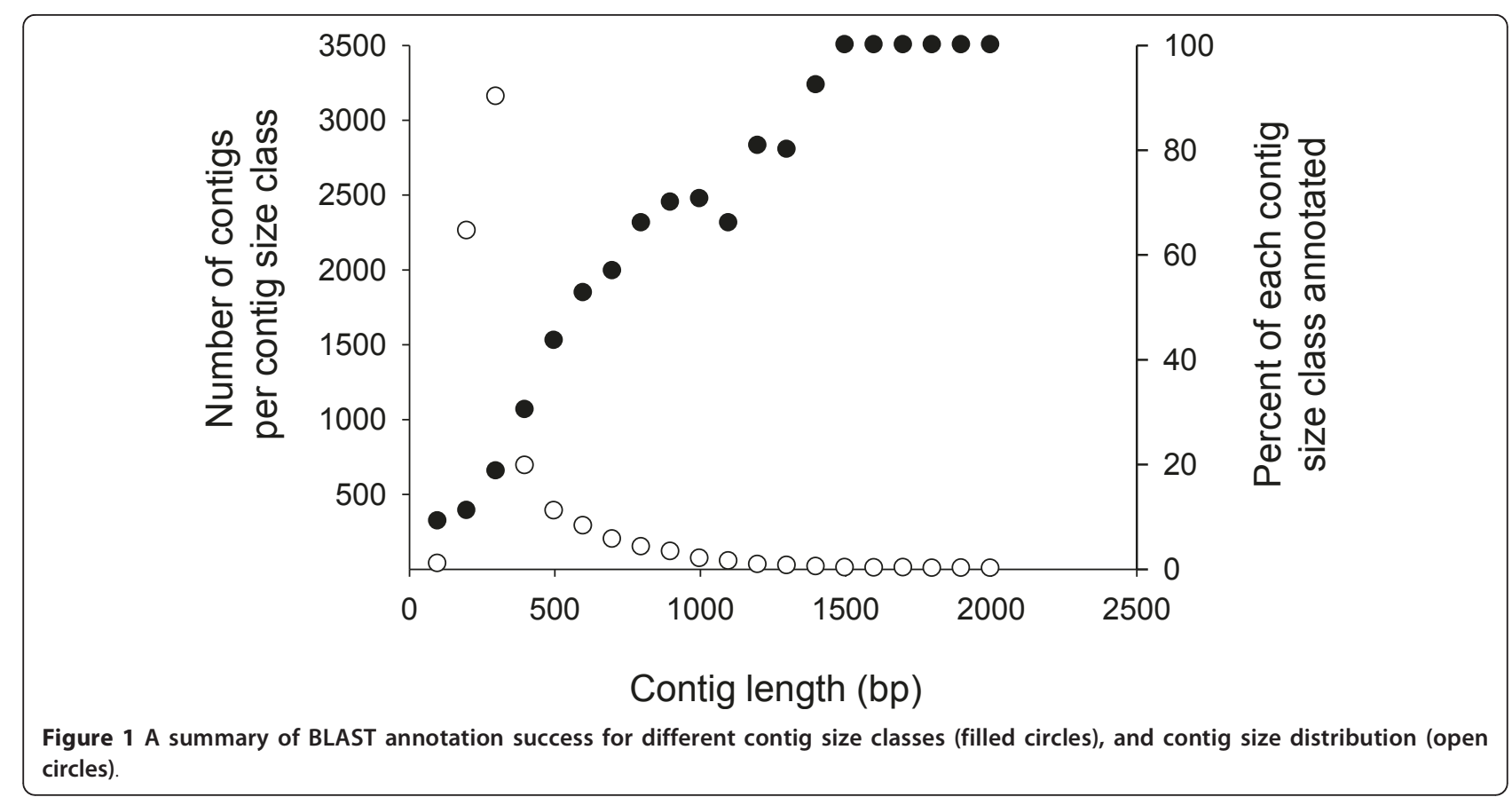

relative to corresponding full length mRNA sequences was examined (Figure 3). For 20 contigs, full length mRNA sequences were available in Genbank for $O$. marina, or from relatively closely related taxa (i.e. basal dinoflagellates or Perkinsus spp). In all cases 454 contigs were truncated and no spliced leader sequences [9] were detected in the dataset. Relative contig length varied between 70 and $15 \%$ of the full mRNA transcript

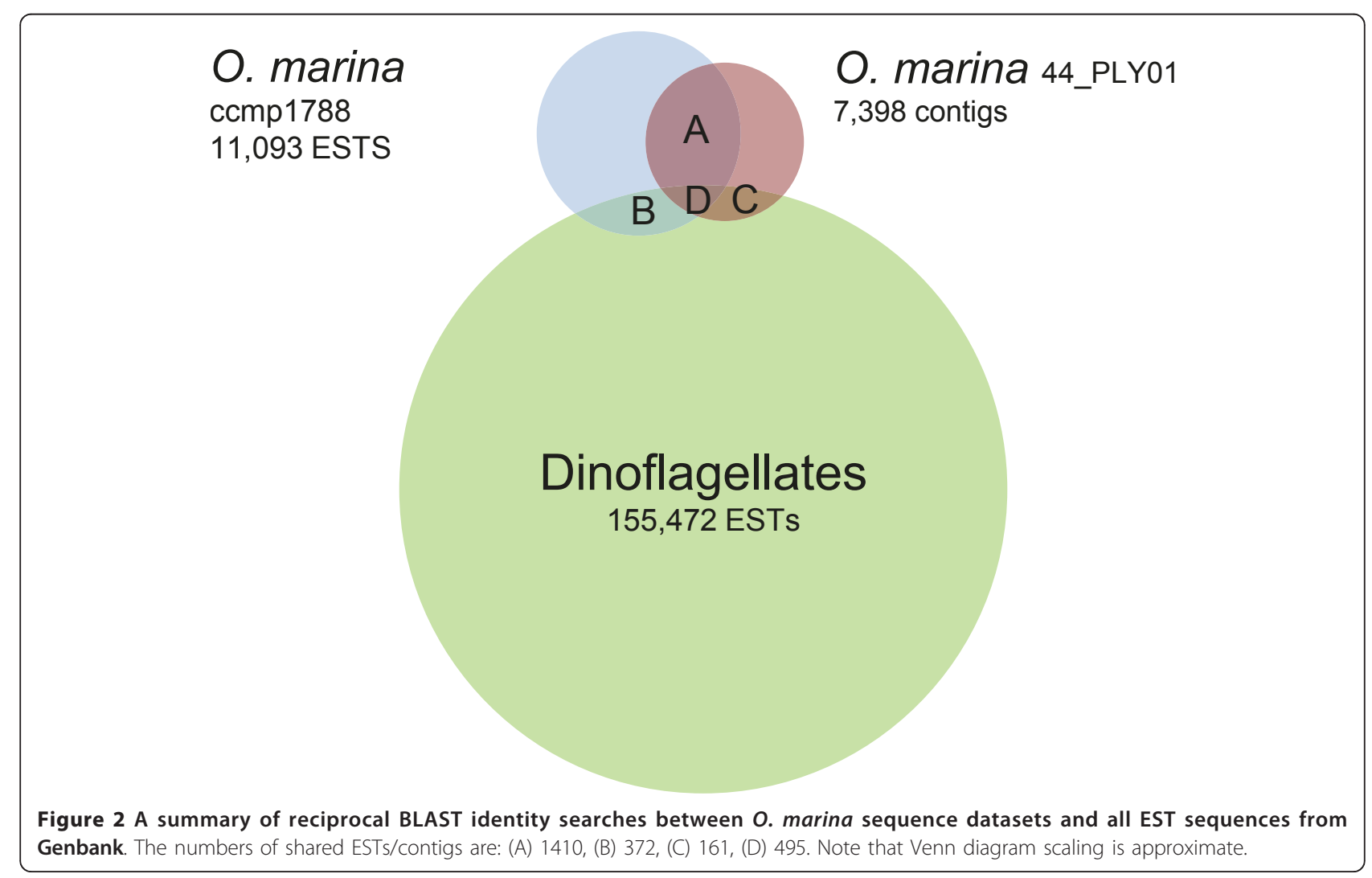




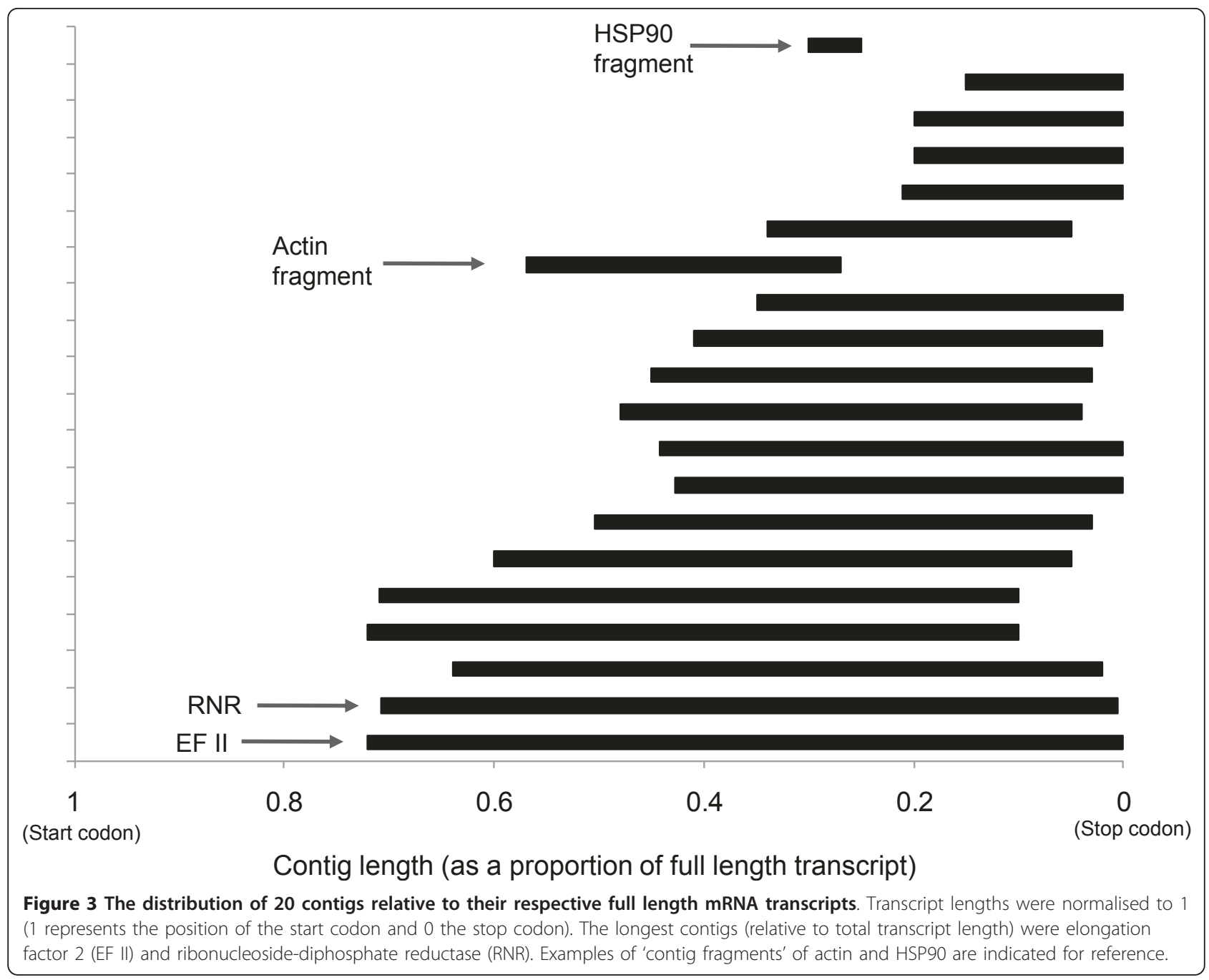

(Figure 3). The most complete identifiable contigs occurred for elongation factor 2 and ribonucleosidediphosphate reductase large subunit (Figure 4a). Shorter contigs tended to cluster at the 3' end of mRNAs thus an overall 3' bias in coverage occurred (Figure 3).

In addition to single contigs some mRNA transcripts were represented as multiple non-overlapping fragments or as variable numbers of substantially overlapping fragments (Figure $4 b, c)$. In the cases where multiple fragments occurred (e.g. HSP90 and Actin) one contig/ fragment was typically highly abundant (Figure 4b). Manual checking of fragment alignments suggested that overlapping regions contained genuine polymorphisms, though the occurrence of multiple non-overlapping fragments is presumably an artefact of library preparation or sequencing (see discussion). The second arrangement, multiple highly overlapping contigs, appears to be a genuine biological signal (Figure 4c). To assess the prevalence, of these expressed gene variants, 454 contigs were further grouped/assembled using CAP3. This higher level assembly of contigs generated 164 gene clusters consisting of 2-28 contigs. In the majority of cases clusters consisted of truncated cDNAs bearing 3' UTR variants with $<100 \mathrm{bp}$ of coding sequence. However, for identified gene clusters, with $>200 \mathrm{bp}$ of coding sequence, variation was predominately synonymous, with $d_{N} / d_{S}$ ratios between 0.33-0.023 (Table 2). For the most extensive gene variant clusters, contigs were predominantly highly overlapping and biased toward the 3' end of mRNAs (e.g. Figure 4c). A similar occurrence of gene variants was evident in the O. marina CCMP1788 EST dataset. An additional CAP3 assembly of the combined $O$. marina data highlighted a limited degree of overlap (74 CAP3 contigs contained sequences derived from both datasets) and 750 gene variant clusters in the CCMP1788 ESTs (Figure 5). The most abundant gene cluster in CCMP1788 consisted of 33 variants, but was not identifiable by BLAST similarity searches 


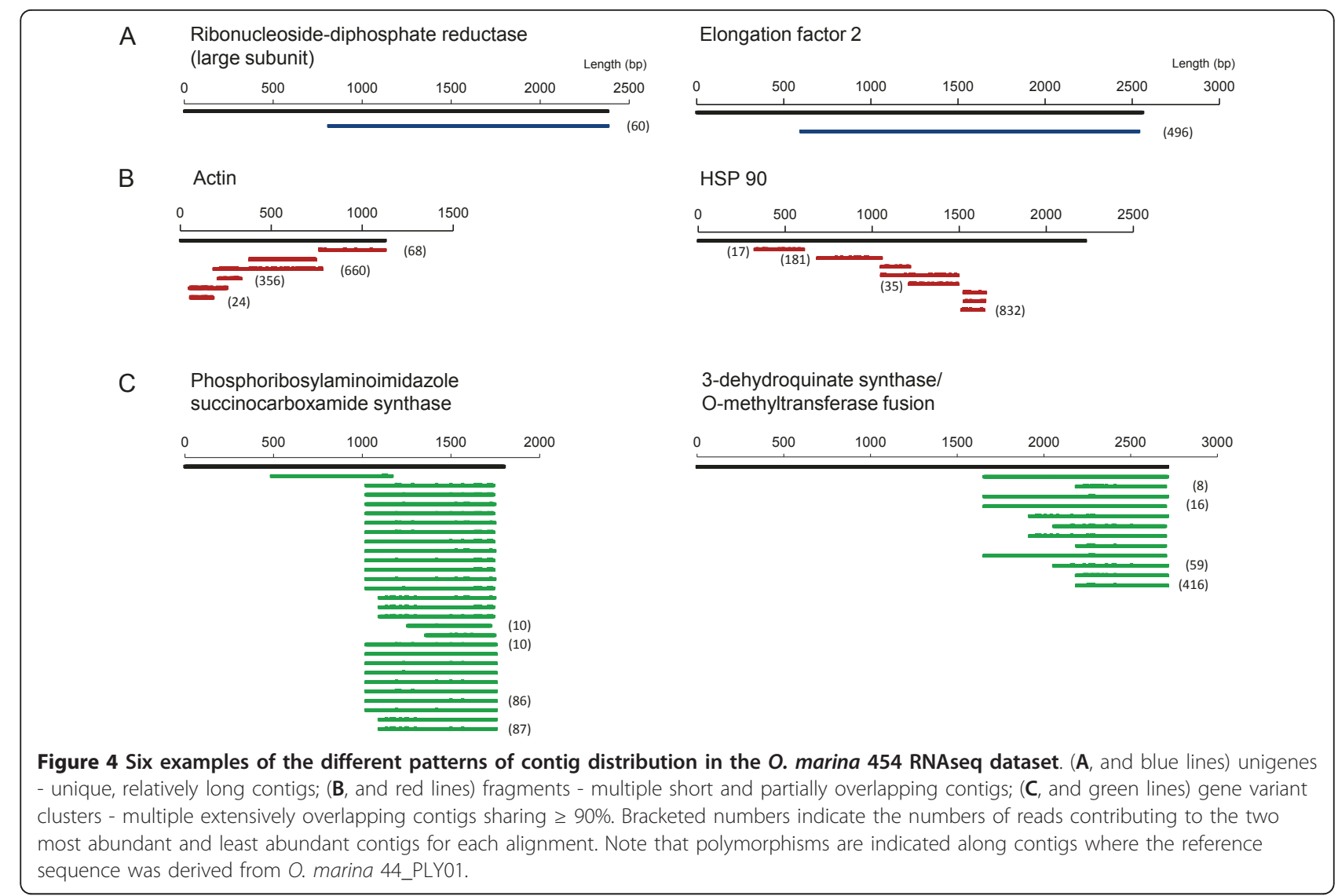

against nr or nt databases. The largest gene variant cluster for which both strains possessed multiple gene variants was a type II rhodopsin gene.

\section{Tandem gene arrangements}

The genomic context of variants was explored for 5 candidate genes (Table 3). In all cases, outward orientated primers designed against cDNA sequences generated
PCR products confirming that genes were present as tandem repeated copies. Subsequent PCR and sequencing confirmed the length of intergenic regions (195415bp). Cloning and sequencing of alpha tubulin and HSP90 PCR amplicons revealed the occurrence of a single 195bp intergenic region (IGR) for alpha tubulin and for HSP90, 6 variable IGRs (Figure 6). By percent identity HSP90 IGRs formed 2 groups ( 82\% identity);

Table 2 A summary of expressed gene variants and their synonymous/non-synonymous substitution rates

\begin{tabular}{|c|c|c|c|c|c|}
\hline Gene & Copies & $\begin{array}{l}\text { Alignment length } \\
\text { (bp) }\end{array}$ & $d_{s}$ & $d_{N}$ & $d_{N} / d_{s}$ \\
\hline $\begin{array}{l}\text { Phosphoribosylaminoimidazole-succinocarboxamide } \\
\text { synthase }\end{array}$ & 27 & 561 & $0.038 \pm 0.011$ & $0.0039 \pm 0.002$ & $0.123 \pm 0.062$ \\
\hline 3-dehydroquinate synthase/O-methyltransferase fusion & 12 & 408 & $0.0304 \pm 0.012$ & $0.008 \pm 0.003$ & $0.3294 \pm 0.152$ \\
\hline Heat shock protein 70 & 8 & 1353 & $0.0218 \pm 0.006$ & $0.0004 \pm 0.004$ & $0.0330 \pm 0.0032$ \\
\hline Calmodulin & 6 & 447 & $\begin{array}{l}0.0221 \pm \\
0.0116\end{array}$ & - & - \\
\hline S-adenosylmethionine synthetase & 5 & 1302 & $\begin{array}{l}0.0294 \pm \\
0.0082\end{array}$ & $\begin{array}{l}0.0007 \pm \\
0.0007\end{array}$ & $\begin{array}{l}0.0226 \pm> \\
0.0001\end{array}$ \\
\hline Chlorophyll a-b binding protein 25 & 2 & 213 & 0.122 & 0.009 & 0.076 \\
\hline Deoxyribonuclease-2-alpha & 2 & 459 & 0.163 & 0.020 & 0.122 \\
\hline Glucose dehydrogenase & 2 & 432 & 0.205 & 0.006 & 0.029 \\
\hline Heat shock protein 90 & 2 & 198 & 0.235 & - & - \\
\hline WD repeat-containing protein & 2 & 190 & 0.170 & - & - \\
\hline
\end{tabular}




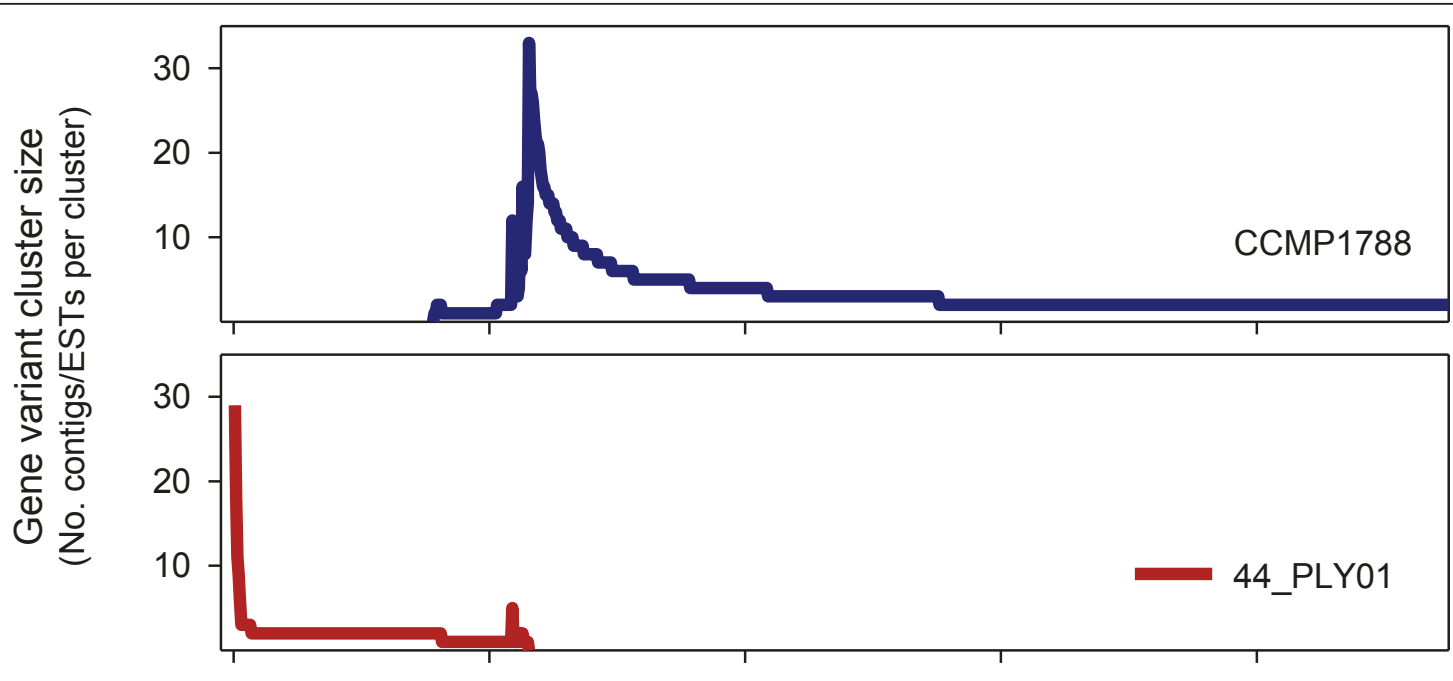

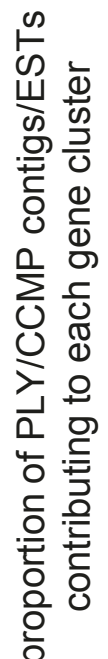

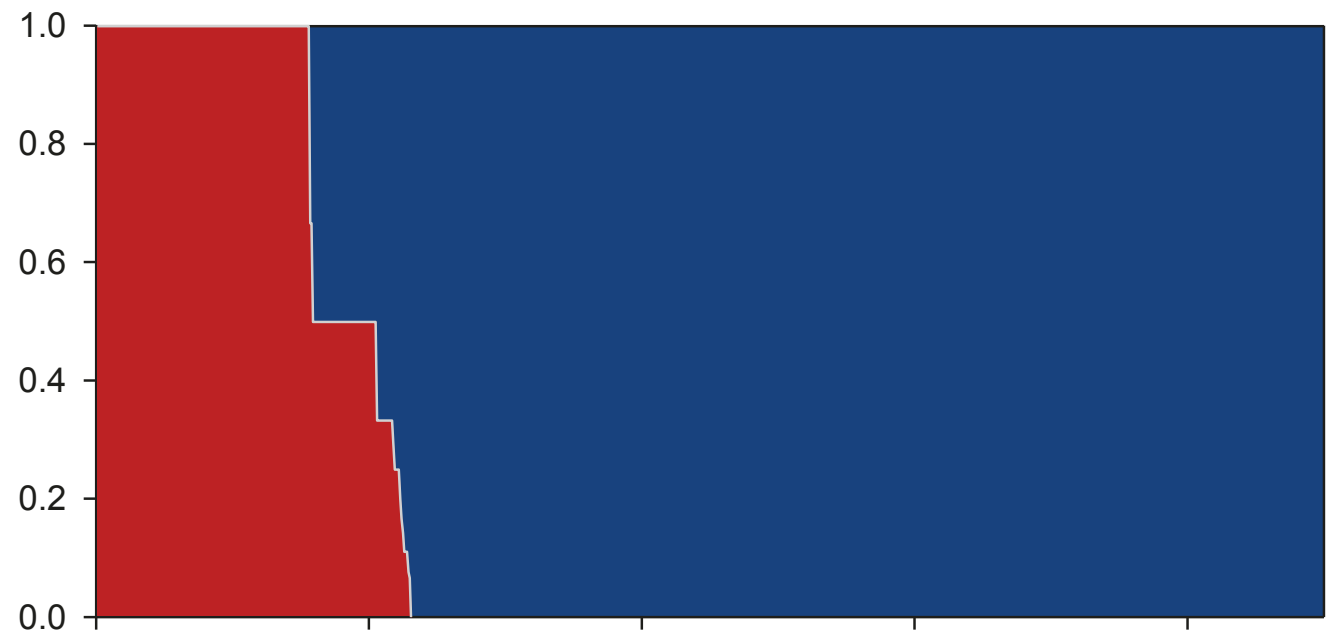

Gene variant clusters $(n=963)$

Figure 5 A comparison of the 454 RNAseq (strain 44_PLY01) and EST (strain CCMP1788) sequence datasets. Sequences were assembled using CAP3 (see methods). Bottom panel: the contribution (as a proportion of the total contigs/ESTS per gene cluster) of 44 _PLY01 contigs (red) and CCMP1788 ESTs (blue) to each gene cluster. Note - columns that are entirely red represent gene clusters composed of 44 _PLY01 contigs only; entirely blue columns represent gene clusters composed of CCMP1788 ESTs only. Middle and top panels: the size (i.e. the number of contributing contigs and/or ESTs) distribution of gene variant clusters in the 44_PLY01 (middle panel) and CCMP1788 (top panel) datasets.

groups 1 and 2 consisted of 1 and 5 IGRs, respectively. Group 2 IGRs were also associated with an aspartic acid/glutamic acid substitution, occurring 28 residues from the stop codon (Figure 6). Five-prime ends of
HSP90 and alpha tubulin cDNAs were confirmed to terminate in a generic dinoflagellate spliced leader sequence; the intergenic spacer/5' UTR boundary was inferred from alignment of cDNAs and genomic

Table 3 Oxyrrhis marina genes occurring in tandem repeats

\begin{tabular}{llll}
\hline Gene & Gene size $(\mathbf{b p})$ & $\begin{array}{l}\text { Tandem repeat? } \\
(\mathbf{Y} \text { - yes, N - no) }\end{array}$ & Intergenic region size (bp) \\
\hline Beta tubulin & - & $Y$ & - \\
Elongation factor 2 & 2499 & $Y$ & 412 \\
Rhodopsin & - & $Y$ & - \\
Alpha tubulin & 1362 & $Y$ & 195 \\
HSP90 & 2121 & $Y$ & $321-340$ \\
\hline
\end{tabular}




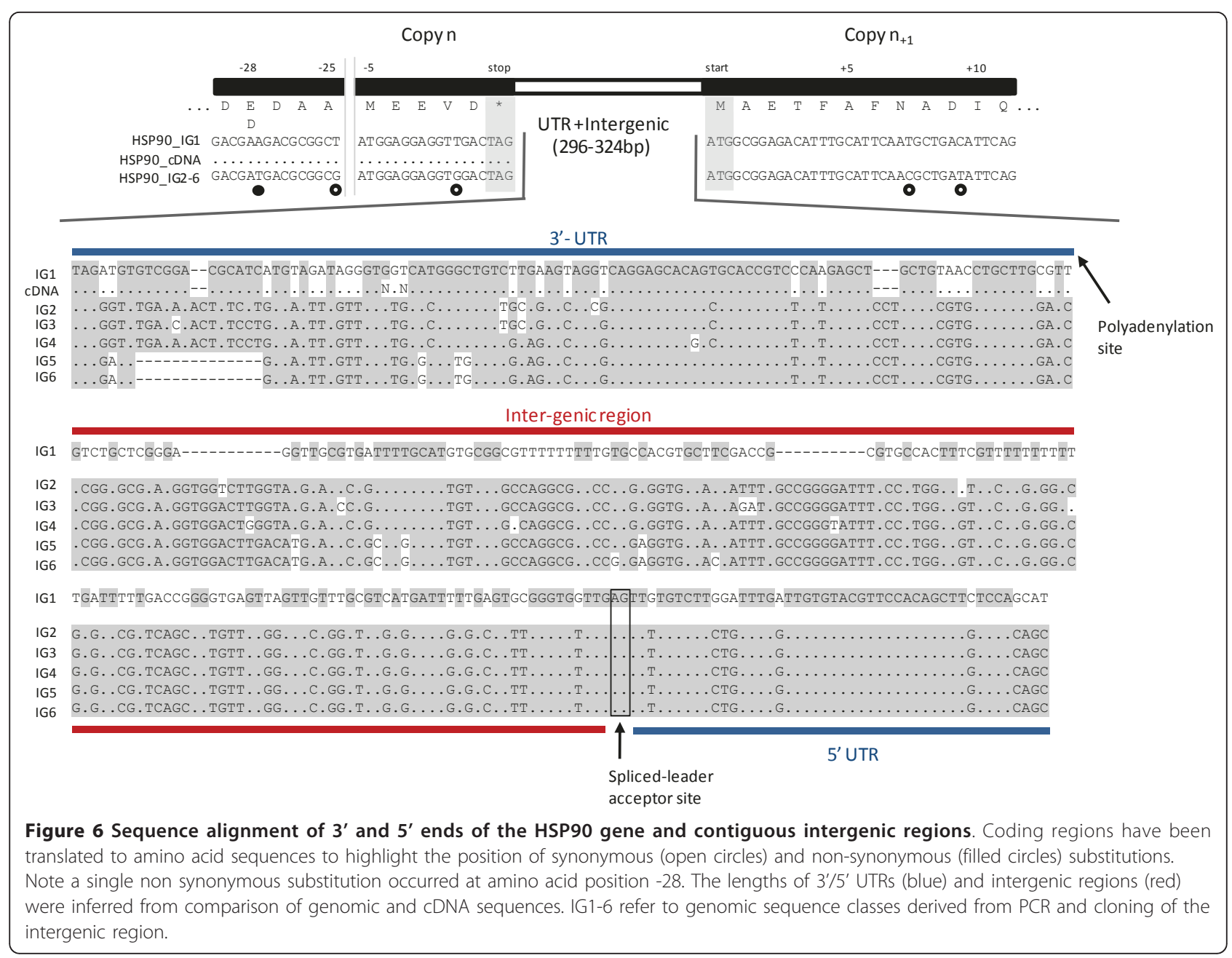

sequences. Five-prime UTRs were 45 and $77 \mathrm{bp}$ in HSP90 and alpha tubulin, respectively. In both cases spliced leader sequences were spliced at an 'AG' acceptor site (Figure 6).

\section{Gene content and functional annotation}

A total of 571 contigs could be assigned to 1 or more GO categories (note that contigs may be assigned to several GO categories). GO annotation for biological processes (Level 3) highlighted the dominance of contigs associated with metabolic processes (46\%), with fewer contigs involved with cellular organisation $(n=11 \%)$ and regulation (4\%; Additional file 3, Figure S1). Similarly, contigs were assigned to a range of Level 3 Cellular Components, including intercellular components, membranes, organelles and protein- and ribonucleoprotein-complexes (Additional file 3, Figure S2).

The functional distribution of the GO-assigned $O$. marina contigs is relatively typical of eukaryotes, representing a broad range of biological processes and cellular components. Notably 60-65 ribosomal proteins
(Additional file 2, Table S3), out of an expected typical eukaryotic complement of 75-80 [35] were present. Figure 7 provides a summary of the distribution of molecular function (Level 3) categories and indicates that the majority of contigs are associated with binding processes $(n=468)$ and catalytic activity $(n=445)$. The most abundant transcripts connected with molecular binding processes include actin ( $n=991$ reads, protein binding), rho-associated protein kinase $2(n=381$ reads, protein binding), V-type proton ATPase catalytic subunit A ( $n=$ 314 reads, nucleotide binding), serine/threonine-protein kinase ( $n=150$ reads, nucleotide binding), DNA replication licensing factor $\mathrm{mcm} 7$ ( $n=123$ reads, nucleotide binding), and nucleoside diphosphate kinase 7 ( $n=119$ reads, nucleotide binding). Abundant contigs were involved with catalysis include cathepsin B-like cysteine proteinase 6 ( $n=1,617$ reads, hydrolase activity), aldehyde dehydrogenase $(n=460$ reads, oxidoreductase activity), 2-nitropropane dioxygenase ( $n=234$ reads, oxidoreductase activity), ankyrin repeat-containing protein $(n=231$ reads, hydrolase activity), calcium- 


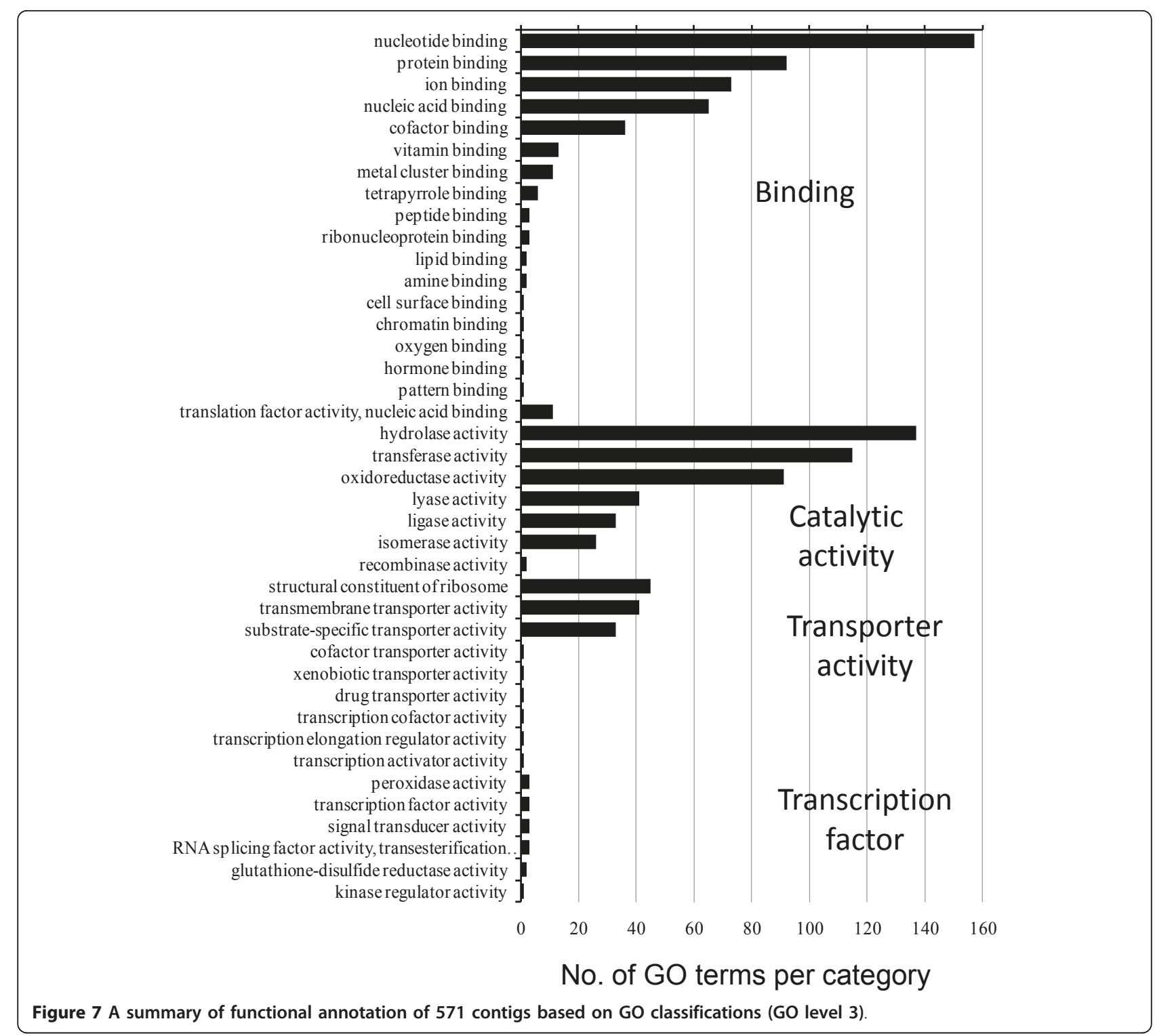

dependent protein kinase $(n=226$ reads, transferase activity), and 2-oxoisovalerate dehydrogenase subunit alpha ( $n=202$ reads, oxidoreductase activity).

A diverse range of genes associated with amino acid synthesis also occurred in the dataset. Based on the KEGG pathways database [36], 18 of the 22 amino acid biosynthesis, metabolism, and degradation pathways had partial representation in the O. marina dataset (Table 4) and 100 genes with discernable function within these pathways were detected (Additional file 4). Genes associated with the biosynthesis of 6 'essential' amino acids (valine, leucine and isoleucine, lysine, phenylalanine, tryptophan) were also present. Three of these amino acid/nitrogen metabolism genes - dihydrodipicolinate reductase 2 (associated with lysine synthesis), glutamine synthetase (associated with nitrogen glutamate synthesis), and ketol-acid reductoisomerase (associated with valine, leucine, and isoleucine biosynthesis) - are typically associated with plastids (Additional file 4, see discussion).

\section{Differential transcript abundance/gene expression in response to salinity}

Growth rate of $O$. marina was significantly higher in the 30 PSU treatment $\left(0.67 \mu, \mathrm{d}^{-1}\right.$ and $0.34 \mu, \mathrm{d}^{-1}$ for 30 and 50 PSU, respectively: $t_{4}=5.72, p<0.01$; Figure 8). Based on an analysis of total read counts, 29 contigs were significantly differentially represented in salinity treatments (Tables 4 and 5). Nine and 20 contigs were over or under expressed (respectively) in the 50 PSU treatment. Of the ostensibly differentially expressed transcripts, 12 were nominally identified by BLAST 
Table 4 Summary of contig assignments to KEGG pathways associated with amino acid biosynthesis and metabolism

\begin{tabular}{|c|c|c|}
\hline $\begin{array}{l}\text { KEGG } \\
\text { ID }\end{array}$ & Kegg pathway & $\begin{array}{l}\text { No. of } \\
\text { contigs }\end{array}$ \\
\hline 00250 & Alanine, aspartate and glutamate metabolism & 8 \\
\hline 00260 & Glycine, serine and threonine metabolism & 11 \\
\hline 00270 & Cysteine and methionine metabolism & 8 \\
\hline 00280 & Valine, leucine and isoleucine degradation & 12 \\
\hline 00290 & Valine, leucine and isoleucine biosynthesis & 3 \\
\hline 00300 & Lysine biosynthesis & 4 \\
\hline 00310 & Lysine degradation & 6 \\
\hline 00330 & Arginine and proline metabolism & 7 \\
\hline 00340 & Histidine metabolism & 2 \\
\hline 00350 & Tyrosine metabolism & 3 \\
\hline 00360 & Phenylalanine metabolism & 4 \\
\hline 00380 & Tryptophan metabolism & 7 \\
\hline 00400 & $\begin{array}{l}\text { Phenylalanine, tyrosine and tryptophan } \\
\text { biosynthesis }\end{array}$ & 4 \\
\hline 00410 & Beta-Alanine metabolism & 6 \\
\hline 00430 & Taurine and hypotaurine metabolism & 2 \\
\hline 00440 & Phosphonate and phosphinate metabolism & 0 \\
\hline 00450 & Selenoamino acid metabolism & 3 \\
\hline 00460 & Cyanoamino acid metabolism & 2 \\
\hline 00471 & D-Glutamine and D-glutamate metabolism & 0 \\
\hline 00472 & D-Arginine and D-ornithine metabolism & 0 \\
\hline 00473 & D-Alanine metabolism & 0 \\
\hline 00480 & Glutathione metabolism & 8 \\
\hline
\end{tabular}

A complete list of assignments, and identifications are included in Additional file 4 .

identity (7 and 5 for 50 and 30 PSU libraries, respectively). Differences in expression varied markedly for transcripts over or under expressed at 50 PSU. For under expressed transcripts, differences ranged between 1.23 and 23 fold; total read counts varied between 26 and 2, 114 and were inversely proportional to fold difference (Table 5). For over expressed transcripts differences ranged between 1.3-1.8 fold, and total read counts varied between 210 and 1, 617 reads (Table 6). A large proportion of contigs $(2,285)$ were rare $(<12$ reads $)$ and occurred in only 1 of the 2 treatments (339 of which were identified). 1, 399 contigs were present in the 30 PSU treatment but absent in 50 PSU; 886 contigs were present at 50 PSU but absent at 30 PSU.

Quantitative PCR validation assays were successful for 13 target genes (2 assays were excluded as a result of poor primer efficiency, and 2 assays were designed against 2 target gene to assess conformity). Target gene expression was normalised to 2 control genes (actin and alpha-tubulin, Figure 8). Six and 4 targets were identified as over or under expressed at 50 PSU, respectively, and greatest fold differences between treatments occurred for beta-tubulin, $40 \mathrm{~S}$ ribosomal protein, and phosphoethanolamine N-methyltransferase (PhNMT) genes. Comparison of relative expression patterns estimated from qPCR and 454 read abundance indicated extensive discrepancies between the 2 approaches. In 6 out of 14 comparisons, the direction of expression differences was the same based on the 2 approaches. In the remaining 8 cases there were substantial differences in relative expression level estimates; for example, estimates of expression for HSP90 were 4.0 fold over expressed at 50 PSU versus 1.8 fold under expressed for 454 and qPCR based estimates, respectively (Figure 8 ).

\section{Discussion}

Oxyrrhis - an emerging genomic model

Recent interest in the genetic and genomic architecture of O. marina has informed the evolutionary history of a range of conspicuous dinoflagellate traits. For example, it is now clear that the RNA trans-splicing mechanism, seemingly ubiquitous within the dinoflagellates, also occurs within $O$. marina and the more distantly related Perkinsus marinus [37], suggesting that trans-splicing was established early in the ancestral lineage leading to the dinoflagellates. In contrast, studies of the mitochondrial genome indicate that the large but highly fragmented structure, again a feature of this taxon, is a more recent trait as it is common to the dinoflagellates and O. marina but probably not to Perkinsus [8]. Perhaps the most conspicuous dinoflagellate feature, the seeming massive genome sizes harboured by some species (up to $215 \mathrm{~Gb}$ [7]), also predates O. marina (a recent estimate places the genome size at $\sim 50 \mathrm{Gbp}$ [15]) but occurred after the divergence of Oxyrrhis/dinoflagellates from Perkinsus, in which the genome is of more typical proportion $(\sim 86 \mathrm{Mb})$. Thus it is clear that $O$. marina is of increasing significance in the study of alveolate evolution.

Here we further indicate that tandem gene arrangements and abundant expressed gene variants are common in O. marina. EST surveys of several dinoflagellates have highlighted the occurrence of multiple transcripts coding for the same gene product $[14,38]$, and detailed studies of specific genes have revealed complex gene arrangements and expressed gene variants in several species (e.g.[39,40]). In O. marina, previous study has shown abundant gene transcript variants for actin, HSP70, and rhodopsin (e.g. $[3,16])$. We indicate the same phenomenon here, with nominally 30 identified expressed genes (and $\sim 130$ anonymous truncated transcripts) present as up to 28 variants, for which the majority of nucleotide variation was synonymous. A comparison with existing ESTs indicates even more extensive gene variant clusters in O. marina CCMP1788. In both cases, a large number of variant clusters were not identifiable by BLAST searches against 


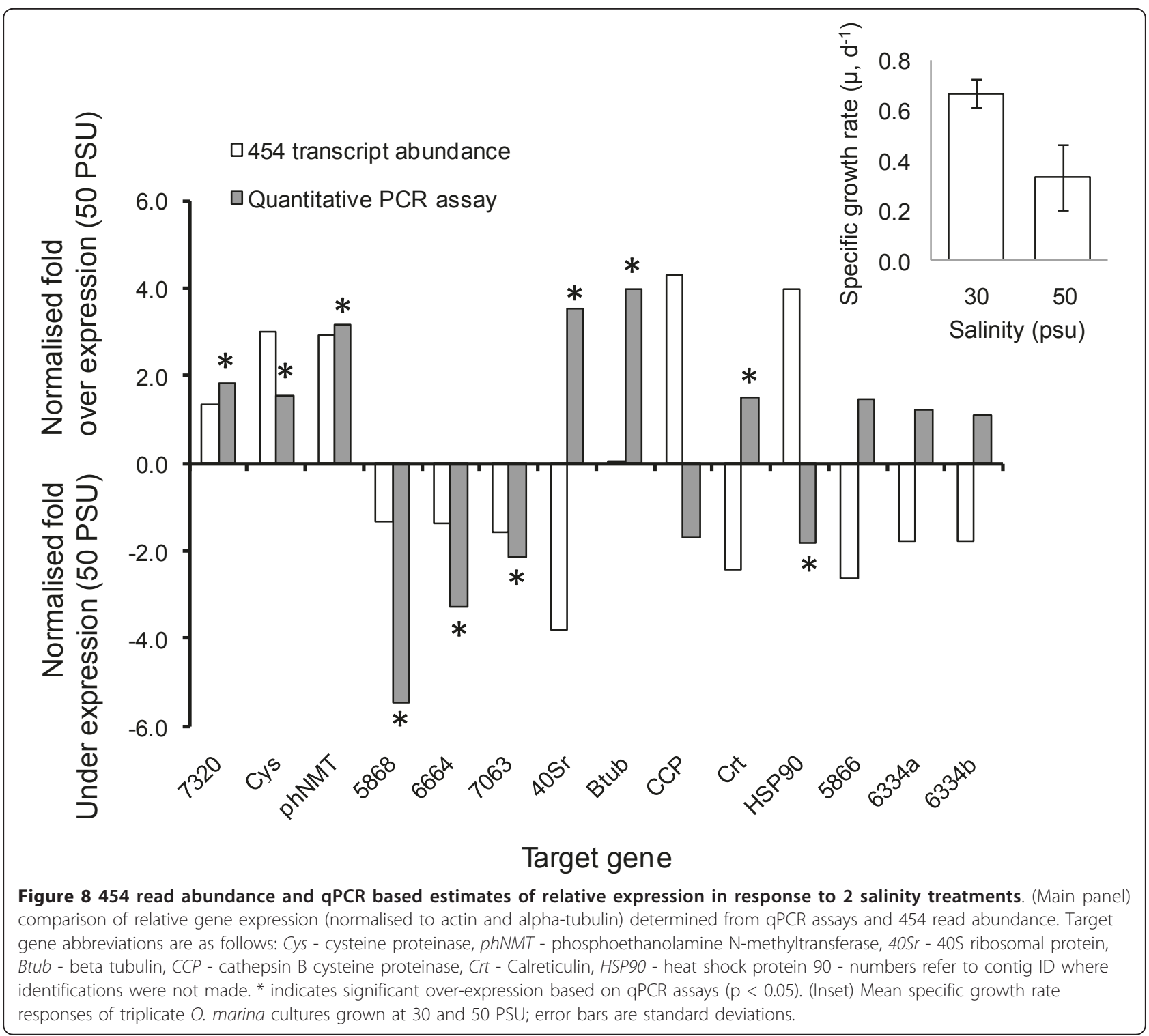

Table 5 Transcripts over expressed at 50 PSU

\begin{tabular}{|c|c|c|c|c|c|c|c|}
\hline \multirow[b]{2}{*}{ Contig } & \multirow[b]{2}{*}{ Length (bp) } & \multirow{2}{*}{$\begin{array}{l}\text { Total } \\
\text { reads }\end{array}$} & \multicolumn{2}{|c|}{$\begin{array}{l}\text { Normalised } \\
\text { abundance }\end{array}$} & \multirow{2}{*}{$\begin{array}{l}\text { Pairwise differential } \\
\text { abundance }(\alpha 0.05)\end{array}$} & \multirow[b]{2}{*}{ ID (BLAST) } & \multirow{2}{*}{$\begin{array}{l}\text { Closest BLAST } \\
\text { hit (GI No.) }\end{array}$} \\
\hline & & & 50 PSU & 30 PSU & & & \\
\hline 05386 & 296 & 160 & 4.3 & 11.3 & & - & - \\
\hline 07320 & 629 & 210 & 14.3 & 8.1 & & - & - \\
\hline 00270 & 1938 & 496 & 32.6 & 19.9 & & elongation factor 2 & 3122059 \\
\hline 06781 & 844 & 387 & 24.9 & 15.9 & $p<0.001$ & deoxyribonuclease-2-alpha & 3182984 \\
\hline 07146 & 780 & 603 & 38.1 & 24.7 & & putative phosphoethanolamine $\mathrm{N}$-methyltransferase 2 & 24212079 \\
\hline 06493 & 249 & 738 & 44.5 & 32.8 & & glyceraldehyde-3-phosphate dehydrogenase & 462139 \\
\hline 06673 & 118 & 1158 & 69.7 & 51.5 & & heat shock protein 90 & 38885054 \\
\hline 06337 & 220 & 893 & 53.7 & 39.8 & & cysteine proteinase precursor & 32172429 \\
\hline 06388 & 572 & 1617 & 94.2 & 74.4 & & cathepsin B-like cysteine proteinase & 1169087 \\
\hline
\end{tabular}


Table 6 Transcripts under expressed at 50 PSU

\begin{tabular}{|c|c|c|c|c|c|c|c|}
\hline \multirow[b]{2}{*}{ Contig } & \multirow[b]{2}{*}{ Length (bp) } & \multirow[b]{2}{*}{ total reads } & \multicolumn{2}{|c|}{ Normalised abundance } & \multirow{2}{*}{$\begin{array}{l}\text { Pairwise differential } \\
\text { abundance }(\alpha 0.05)\end{array}$} & \multirow[b]{2}{*}{ ID (BLAST) } & \multirow{2}{*}{$\begin{array}{l}\text { closest BLAST } \\
\text { hit (GI No.) }\end{array}$} \\
\hline & & & 50 PSU & 30 PSU & & & \\
\hline 05236 & 109 & 26 & 0.1 & 2.3 & & - & - \\
\hline 06334 & 295 & 119 & 1.1 & 9.3 & & - & - \\
\hline 00224 & 199 & 35 & 0.4 & 2.9 & & - & - \\
\hline 06976 & 117 & 295 & 3.6 & 24.2 & & putative fumarate reductase & 74581896 \\
\hline 07063 & 294 & 148 & 3.1 & 10.4 & & - & - \\
\hline 06664 & 272 & 131 & 3.2 & 9.5 & & - & - \\
\hline 06325 & 275 & 442 & 11.3 & 31.6 & & - & - \\
\hline 05868 & 162 & 138 & 3.6 & 9.8 & & - & - \\
\hline 05866 & 175 & 279 & 7.1 & 19.1 & & - & - \\
\hline 04983 & 255 & 111 & 2.8 & 7.1 & $p<0.001$ & - & - \\
\hline 06926 & 166 & 179 & 5.1 & 11.7 & & - & - \\
\hline 05228 & 243 & 192 & 6.4 & 12.6 & & - & - \\
\hline 05401 & 151 & 336 & 11.2 & 21.1 & & - & - \\
\hline 05956 & 131 & 691 & 26.2 & 42.8 & & - & - \\
\hline 06694 & 123 & 480 & 18.2 & 29.7 & & - & - \\
\hline 06660 & 221 & 632 & 26.2 & 37.4 & & calreticulin precursor & 11131631 \\
\hline 07447 & 146 & 725 & 30.5 & 42.5 & & - & - \\
\hline 05032 & 247 & 1058 & 46.8 & 60.3 & & conserved hypothetical protein & 239877215 \\
\hline 07041 & 200 & 1520 & 68.3 & 85.7 & & 40 S ribosomal protein S25 & 112253591 \\
\hline 06775 & 258 & 2114 & 96.4 & 118.2 & & $60 S$ ribosomal protein L26-1 & 27735242 \\
\hline 05386 & 296 & 160 & 4.3 & 11.3 & & - & - \\
\hline
\end{tabular}

Genbank databases and no obvious functional class of genes appeared to dominant the most abundant variant clusters. For 44_PLY01 the largest gene cluster occurred for phosphoribosylaminoimidazole-succinocarboxamide synthase, a gene associated with purine metabolism [41], and the largest variant cluster in CCMP1788 coded for a type II rhodopsin gene. Notably, Slamovits et al. [16] have described $\sim 50$ variants encoding rhodopsin in strain CCMP1788; here we detected far fewer variants (2-4 rhodopsin contigs). This discrepancy may simply be a result of different methodologies. Oxyrrhis marina cultures in this study were grown in the dark, and given the likely role of rhodopsin in phototaxis [42], it would seem a potential that this treatment may reduce rhodopsin expression. Alternatively, differences in gene variant abundance may occur between strains. Whether structural or transcriptional differences exist at this level has yet to be examined, though global comparisons of the 44_PLY01 and CCMP1788 datasets using BLAST and CAP3 (Figures 2 and 5) both highlighted limited similarity $(\sim 15 \%$ of ESTs/contigs were common to both strains). We have previously documented extensive genetic diversity within O. marina [43] and strains CCMP1788 and 44_PLY01 occur within different $O$. marina clades (44_PLY01 and CCMP1788 occur within clades 1 and 2, respectively) based on sequence variation at 2 gene loci $[1,24]$. Whilst it is beyond the scope of the current study, it is likely that comparative assessments of gene/genome complement, arrangement, and structure at a range of phylogenetic between basal dinoflagellates will be highly informative. In particular, such comparative strategies will be useful to assess the rate of change of, for example, gene copy number at a key evolutionary juncture within the alveolates.

In addition to the occurrence of extensive expressed gene variants we have also shown that genes encoding transcribed variants occur as tandem repeated arrays in O. marina, an arrangement that has been demonstrated for a number of other dinoflagellate taxa [14]. The 5 genes examined here (Table 3) were each arrayed in tandem, separated by short intergenic regions. HSP90 occurs in several contexts, with 2 major variants of the intergenic region; notably however, based on 3' UTR sequence the variants detected in a genomic context did not tally with those present in the RNAseq dataset. Given that mRNA sequences for HSP90 were fragmented and incomplete at the 3' end it is most likely that the corresponding portion of transcripts were simply missing in the RNAseq data, though it is also possible that we have under sampled the existing variation for this gene. In contrast, only a single intergenic sequence was recovered for alpha tubulin, which did match the mRNA sequence. In both cases cDNAs were transspliced, a universal feature of dinoflagellate transcription [9], and the trans-splicing acceptor site corresponded to an 'AG' signal as noted in other dinoflagellates [14]. Of 
course, as a result of potential amplification biases associated with PCR detection, the actual diversity of intergenic regions is difficult to assess; nevertheless the occurrence of tandem gene repeats separated by different intergenic spacers suggests a number of potential genomic arrangements. Different intergenic spacers potentially indicate the occurrence of multiple tandem arrays at different genomic loci. Alternatively, individual arrays may be a complex arrangement of gene copies and heterogeneous intergenic spacers. Notably an in situ hybridisation based study of several genes in O. marina indicated 3, 4, and 5 genomic locations for actin, alpha tubulin, and HSP90 [15]. The precise structure and the extent of these tandem gene arrays remains to be investigated in $O$. marina; regardless, it is now increasingly clear that gene duplication is extensive in dinoflagellates more generally, and results in complex gene arrangements (e.g. [13,39]. Understanding the mechanisms promoting such expansions is an important focus for dinoflagellate genome biologists. A systematic survey of the arrangement of such duplicated genes will be informative and given the basal position of Oxyrrhis it will almost certainly prove valuable for establishing the likely origin of extensive duplication in the dinoflagellate lineage.

\section{The gene complement of $O$. marina}

Analysis of the existing CCMP1788 EST dataset identified a range of $O$. marina genes indicative of significant evolutionary processes [3]. Oxyrrhis marina possesses genes such as proteorhodopsins that appear to have been laterally transferred from a bacterial origin [16] and a number of plastid genes, including ketol-acid reductoisomerase, carbonic anhydrase, and cysteine synthase, which suggests an evolutionary ancestry that included a chloroplast bearing cell [10]. In this study, we highlight the occurrence of a broad range of genes associated with amino acid synthetic and metabolic pathways, including genes which indicate the ability to synthesise 'essential' amino acids, a capacity not typical in heterotrophic protists. Molecular evidence for extensive biosynthetic capacities certainly supports previous study on the nutritional biochemistry of $O$. marina. A series of comprehensive studies of nutritional physiology by MR Droop and co-workers (e.g. $[25,44])$ highlighted that, in addition to phagotrophy, O. marina displayed a "plant-like" biochemistry including the ability to synthesise the full complement of amino-acids from ammonium or other simple nitrogen sources. While amino acid biosynthesis capability in heterotophic protists is exceptionally diverse, an absolute requirement for several amino acids is typical [45]. A broad range of transcripts indentified in this study were associated with amino acid metabolism and biosynthesis; based on the
KEGG databases [36], 18 of the 22 amino acid biosynthesis pathways were represented by 100454 contigs. The ability to undertake population growth on a fully synthetic medium with relatively simple absolute requirements (acetic acid or ethanol; valine, alanine; biotin; thiamine; vitamin B1s; ubiquinone; and a sterol [46]) and an exceptionally broad phagotrophic capacity (35-40 different prey items are documented as supporting $O$. marina population growth in vitro [27]) make O. marina exceptional. One mechanism by which $O$. marina may have gained its biosynthetic capacity is via an ancestral plastid or ancestral cyanobacterial endosymbiont [3]. The occurrence of plastid targeting signalling peptides and genes that are almost certainly plastid or cyanobacterial in origin (e.g. those coding for 1-deoxyD-xylulose-5- phosphate reductoisomerase, haem, carbonic anhydrase, ketol-acid reductoisomerase, and dihydrodipicolinate reductase [3], and this study) are certainly strong support for such a mechanism.

More generally, based on GO and BLAST annotations a broad range of gene families and metabolic processes are nominally represented in the $O$. marina RNAseq library presented here. However, estimation of transcriptomic diversity, the comprehensiveness of the sequencing, and thus the likely gene complement of O. marina is difficult in the absence of a reference or close reference genome. Estimates of gene content based on genome size are possible; recent work by Hou and Lin [47] shows a strong non-linear correlation between genome size and protein-coding gene number across a broad range of eukaryotes. Hou and Lin [47] estimate total gene content of the largest dinoflagellate genomes to be on the order of $80-90,000$ genes comprising $\sim 1 \%$ of the total genome. An estimated DNA content for O. marina of $\sim 55.8 \mathrm{pg} \mathrm{cell}^{-1}$ [15] places its genome within the dinoflagellate range ( $\sim 50 \mathrm{Gbp})$ and suggests some $\sim 70$, 000 genes (assuming an average eukaryotic gene size of $1.3 \mathrm{Kbp}$ [47]). Gene-content predictions of this magnitude are exceptionally high in comparison to other eukaryotes; however, as noted above, many genes in dinoflagellates occur in high copy numbers (up to 5, 000 gene copies in some cases, e.g. [40]); thus, it is possible that much of the 'gene space' in dinoflagellates is occupied by multi-copy genes and the total proteomic diversity is closer to that displayed by eukaryotes more generally [47].

The representation of conserved gene classes also provides an approximate indication of transcriptome coverage. In this study we detected 61 ribosomal protein coding transcripts of the 75-80 that are typical of most eukaryotes [35]; while contigs did not represent full transcripts and such a comparison can only give a crude estimate these figures suggest a representation in the region of $75 \%$ of the transcriptome. It should be noted 
however, that comparison of the RNAseq and EST datasets for $O$. marina potentially conflict with this estimate. Assuming strains are relatively similar (sequence divergence based on mitochondrial cytochrome oxidase I is $\sim 2 \%$ [24]), the degree of overlap in transcriptome sequence datasets between strains was relatively small ( $15 \%)$, potentially indicating a high degree of undersequencing in both cases. Of course, strains might differ more than suspected, or biases in sequencing (e.g. truncation or fragmentation of transcripts) might reduce overlap between the datasets. In either case, it seems clear that comprehensive sampling of the $O$. marina transcriptome is likely to require a further substantial sequencing effort.

\section{Transcriptomic novelty and the problem of identification by identity}

We have identified a number of interesting features of the $O$. marina transcriptome adding to previous descriptions of an unusual gene content in this organism. However, the majority of the sequences generated in this study were not identified by identity searches. This limited identification success, whilst partially accounted for by a 3' bias in this dataset (and thus a high representation of UTR sequence), is nevertheless diagnostic of a broader difficultly for genomic studies of dinoflagellates. While, the dinoflagellates are increasingly regarded as important targets for the study of genome evolution, large scale sequence resources are only relatively recently accumulating $[21,22,48,49]$. This poor sequence representation has an impact on the current use of such databases for sequence identification. For example, within the NCBI databases, EST datasets (totalling 155, 474 sequences) exist for only 21 dinoflagellate species, and the majority of ESTs $(122,235)$ are derived from just 5 species. Similarly, in a genomic context, only a handful of plastid genomes and genome sequence surveys exist for dinoflagellates and the majority of nucleotide sequences are environmental rDNAs. Consequently, identification of new sequences via database searches presents a significant challenge for dinoflagellate taxa.

In context, the relatively low annotation rate achieved in this study is, therefore, not surprising. EST projects on metazoa, with relatively close ancestry to many genomic model organisms, can yield high proportions of ESTs (e.g. > 95\%) that are identified by reference to existing sequence databases (e.g. [50]). By contrast, only $1,890(16 \%)$ contigs were identified for O. marina, and less than $2 \%$ of transcripts matched to a single relatively closely related species, such as Perkinsus marinus. Comparably low rates of annotation have been reported for other dinoflagellate EST projects, with only $9 \%$ of the $(\sim 1,400)$ ESTs isolated from Alexandrium ostenfeldii homologous to known proteins [48] and $\sim 20 \%$ (of 6 ,
723) of ESTs from Alexandrium tamerense identified [21]. While ESTs from a number of other eukaryotic protist taxa, for example diatoms, do not appear to be so different from the protein and transcript data available in public databases, a typical annotation rate of $\sim 50 \%$ of transcripts again highlights gaps in genomic information $[48,51]$. Most notably a recent EST project on Perkinsus marinus generated $\sim 31,000$ EST sequences, clustered into $\sim 8,000$ unique sequences of which 55\% were identified [37]; possibly the higher annotation rate in this case is a result of the closer (relatively) phylogenetic affinity between Perkinsus and the Apicomplexa (a group that is well characterised by virtue of containing numerous parasites of humans and livestock). It is notable that only $145 \mathrm{O}$. marina transcripts produced significant identity to $P$. marinus sequences, and only 161 matches occurred between $O$. marina contigs and those from other dinoflagellate taxa. Whether, this is a genuine result of a high degree of novelty of the $O$. marina genome or a simple result of limited genomic data can only be confirmed by further genome scale sequencing, although inferences from phylogenetic analysis do suggest that Oxyrrhis represents a highly divergent and novel lineage [4].

\section{Identification of salinity tolerance mechanisms by differential gene expression}

The application of next-generation sequencing technology to directly characterise transcript abundance is an increasingly used strategy for gene expression profiling [52-54]. The most precise strategies quantify either 5'or 3' (or both) cDNA fragments and thus overcome potential biases associated with sequence read length and incomplete reverse transcription [55]; but for species that lack genome references (for fragment mapping) this approach negates the generation of full or near full length coding sequences, which are typically a valuable output of transcriptome sequencing projects in the case of poorly characterised organisms. Our aim here was to determine whether a de novo transcript assembly can be used concurrently with an experiment to obtain an informative gene expression profile.

Comparisons of transcript abundance profiles for cells grown under 2 salinity treatments nominally identified differing gene expression patterns and in combination with growth rate estimates seemed to provide evidence for specific physiological responses and a tangible molecular mechanism. A higher maximum grow rate at 30 PSU, was concurrent with a relatively strong induction of $\sim 20$ transcripts at this salinity. Likewise, a reduced growth rate and modest induction of a different set of 8 genes occurred at 50 PSU. However, agreement between transcript abundance and qPCR gene expression estimates were relatively poor, both in terms of direction 
and magnitude, and in only 6 out of 14 assays were expression estimates similar. In a broader context, gene expression patterns derived via different methodologies (e.g. qPCR vs. microarray platforms) often do not strongly correlate, although there appears to be more concordance between qPCR and next-generation sequencing platforms than with microarrays (cf. $[53,54]$ ), which may relate to overall transcript abundance [52]. It is clear from a range of studies that some features of next generation sequencing protocols not specifically designed/targeted to quantify transcript abundance potentially generate significant biases in representation (e.g. [56]). From the study presented here for example, the representation of a number of gene transcripts in the $O$. marina RNAseq dataset by numerous non-overlapping fragments (with differing read abundances) is clearly problematic and is likely a result of either incomplete cDNA synthesis and/or a proportion of read assembly errors. Likewise, the occurrence of extensive expressed gene variants, seemingly common in most dinoflagellates has the potential to result in extensive discrepancy between sequence and $\mathrm{qPCR}$ bases approaches; particularly if qPCR assays co-amplify extensive gene variant families.

Accepting the above issues, those genes whose expression profiles were confirmed by qPCR did tentatively suggest a potential underlying salinity response. In 3 cases qPCR and 454 expression estimates identified genes as up regulated at 50 PSU; most notable was the up regulation of phosphoethanolamine N-methyltransferase - this enzyme is a component of a common pathway in plants that generates the osmoprotectant glycine betaine [57]. Thus, increased salinity appears to elicit a decrease in specific growth rate and tentatively a concurrent osmoregulatory response. Clearly such an inference is speculative and confirmation of the occurrence of this metabolic pathway in O. marina is required.

\section{Conclusion}

We have generated some 7,398 cDNA sequence contigs for the basal dinoflagellate O. marina. BLAST searches identified $\sim 14 \%$ of contigs; this relatively modest level of identification is likely due to O. marina's unusual phylogenetic position and the limited sequence data for dinoflagellate taxa more generally. Nonetheless, we have identified a large number of transcripts associated with amino acid biosynthesis, and demonstrated the occurrence of extensive expressed gene variants and tandem gene arrangements; thus further highlighting the utility of next-generation sequencing platforms for generating de novo large scale sequence data to characterise nongenetic-model taxa. Additionally in this study, comparisons of relative read abundance of cells grown under differing osmotic stress nominally identified $\sim 30$ genes differentially regulated in response to salinity. While agreement between sequencing and qPCR based gene expression estimates was relatively poor; qPCR expression data tentatively identified candidate genes for further study of salinity tolerance in this taxon. In an evolutionary context, this is one of the first 454-based transcriptome surveys of an ancestral dinoflagellate taxon and will undoubtedly prove useful for future comparative studies aimed at reconstructing the origin of novel features of the dinokaryon. In an ecological context, these data highlight candidate genes for further research into potential adaptive mechanisms behind broad geographic distributions in eukaryotic microbes.

\section{Additional material}

Additional file 1: Oxyrrhis marina 454 contigs. Text file containing 7, 398 fasta-formatted sequences generated by Newbler (Roche 454) assembly.

Additional file 2: supplementary information for the BLAST identification of Oxyrrhis marina transcripts. This file (.doc) contains summary tables of the longest contigs (Table S1) and the most abundant contigs (Table S2) and corresponding identifications (assigned by BLAST identity). Table S3 provides a summary of the ribosomal protein encoding genes present in the dataset.

Additional file 3: supplementary information for GO annotation of the Oxyrrhis marina transcripts. This file (.doc) contains summaries of annotations for GO biological processes level 3 (Figure S1) and GO cellular component level 3 (Figure S2).

Additional file 4: supplementary information for contigs associated with KEGG amino acid synthesis pathways. Data file (.CSv) containing a summary of contigs associated with amino acid synthesis and a contig identification based on KEGG orthology.

\section{Acknowledgements and funding}

This work was supported by a NERC grant (NE/F005237/1) awarded to PCW, DJSM, and CDL. We would like to thank Dr Margret Hughes of the Liverpool CGR for conducting 454 sequencing, and Dr Kevin Ashelford for invaluable scripting and bioinformatics support.

\section{Authors' contributions}

PCW, DJSM, and CDL conceived and designed the study; CDL and LEM conducted culturing and molecular biology laboratory work; NS, LVM, CDL, and PCW undertook data analyses; all authors contributed to the manuscript. All authors read and approved the final manuscript.

Received: 6 June 2011 Accepted: 20 October 2011

Published: 20 October 2011

\section{References}

1. Lowe CD, Keeling PJ, Martin LE, Slamovits CH, Watts PC, Montagnes DJS: Who is Oxyrrhis marina? Morphological and phylogenetic studies on an unusual dinoflagellate. Journal of Plankton Research 2011, 33:555-567.

2. Montagnes DJS, Lowe CD, Roberts EC, Breckels MN, Boakes DE, Davidson K, Keeling PJ, Slamovits CH, Steinke M, Yang Z, Watts PC: An introduction to the special issue: Oxyrrhis marina, a model organism? Journal of Plankton Research 2011, 33:1-6.

3. Slamovits CH, Keeling PJ: Contributions of Oxyrrhis marina to molecular biology, genomics and organelle evolution of dinoflagellates. Journal of Plankton Research 2011, 33:591-602.

4. Saldarriaga JF, McEwan ML, Fast NM, Taylor FJR, Keeling PJ: Multiple protein phylogenies show that Oxyrrhis marina and Perkinsus marinus 
are early branches of the dinoflagellate lineage. Int I Syst Evol Microbiol 2003, 53:355-365.

5. Saldarriaga JF, Taylor F, Cavalier-Smith T, Menden-Deuer S, Keeling PJ: Molecular data and the evolutionary history of dinoflagellates. European Journal of Protistology 2004, 40:85-111.

6. Kato KH, Moriyama A, Itoh TJ, Yamamoto M, Horio T, Huitorel P: Dynamic changes in microtubule organization during division of the primitive dinoflagellate Oxyrrhis marina. Biology of the Cell 2000, 92:583-594.

7. Hackett JD, Anderson DM, Erdner DL, Bhattacharya D: dinoflagellates: a remarkable evolutionary experiment. American Journal of Botany 2004, 91:1523-1534, 2004

8. Slamovits CH, Saldarriaga JF, Larocque A, Keeling PJ: The highly reduced and fragmented mitochondrial genome of the early-branching dinoflagellate Oxyrrhis marina shares characteristics with both apicomplexan and dinoflagellate mitochondrial genomes. Journal of molecular biology 2007, 372:356-68.

9. Zhang H, Hou Y, Miranda L, Campbell DA, Sturm NR, Gaasterland T, Lin S: Spliced leader RNA trans-splicing in dinoflagellates. Proc Natl Acad Sci USA 2007, 104:4618-4623.

10. Slamovits $\mathrm{CH}$, Keeling PJ: Plastid-derived genes in the nonphotosynthetic alveolate Oxyrrhis marina. Molecular Biology and Evolution 2008, 25:1297-306

11. LaJeunesse T, Lambert G, Andersen RA, Coffroth MA, Galbraith DW: Symbidiniun (Pyrrhophyta) genome sizies (DNA content) are smallest among dinoflagellates. Journal of Phycology 2005, 41:880-886.

12. Veldhuis MJW, Cucci $T L$, Sieracki ME: Cellular DNA content of marine phytoplankton using two new fluorochromes: taxonomic and ecological implications. Journal of Phycology 1997, 33:527-541.

13. Le QH, Markovic P, Hastings JW, Jovine RVM, Morse D: Structure and organization of the peridinin-chlorophyll a-binding protein gene in Gonyaulax polyedra. Molecular \& General Genetics 1997, 255:595-604.

14. Bachvaroff TR, Place AR: From stop to start: tandem gene arrangement, copy number and trans-splicing sites in the dinoflagellate Amphidinium carterae. PLOS ONE 2008, 3:e2929.

15. Sano J, Kato KH: Localization and copy number of the protein-coding genes actin, alpha-tubulin, and HSP90 in the nucleus of a primitive dinoflagellate, Oxyrrhis marina. Zoological Science 2009, 26:745-53.

16. Slamovits C, Okamoto N, Burri L, Erik RJ, Keeling PJ: A bacterial proteorhodopsin proton pump in marine eukaryotes. Nature Communications 2011, 2:183-6.

17. Luikart G, England PR, Tallmon D, Jordan S, Taberlet P: The power and promise of population genomics: from genotyping to genome typing. Nat Rev Genet 2003, 4:981-994.

18. Hudson ME: Sequencing breakthroughs for genomic ecology and evolutionary biology. Molecular Ecology Resources 2008, 8:3-17.

19. Meyer E, Aglyamova GV, Wang S, Buchanan-Carter J, Abrego D, Colbourne JK, Willis BL, Matz MV: Sequencing and de novo analysis of a coral larval transcriptome using 454 GSFIx. BMC Genomics 2009, 10:219.

20. Vera JC, Wheat CW, Fescemyer HW, Frilander MJ, Crawford DL, Hanski I, Marden JH: Rapid transcriptome characterization for a nonmodel organism using 454 pyrosequencing. Molecular Ecology 2008, 17:1636-47.

21. Hackett JD, Scheetz TE, Yoon HS, Soares MB, Bonaldo MF, Casavant TL, Bhattacharya $D$ : Insights into a dinoflagellate genome through expressed sequence tag analysis. BMC Genomics 2005, 6:80.

22. Moustafa A, Evans AN, Kulis DM, Hackett JD, Erdner DL, Anderson DM, Bhattacharya D: Transcriptome profiling of a toxic dinoflagellate reveals a gene-rich protist and a potential impact on gene expression due to bacterial presence. PLOS ONE 2010, 5:e9688.

23. Davidson K, Sayegh F, Montagnes DJS: Oxyrrhis marina-based models as a tool to interpret protozoan population dynamics. Journal of Plankton Research 2011, 33:651-663.

24. Lowe CD, Montagnes DJS, Martin LE, Watts PC: Patterns of genetic diversity in the marine heterotrophic flagellate Oxyrrhis marina (Alveolata: Dinophyceae). Protist 2010, 161:212-21.

25. Droop MR: Water-soluble factors in the nutrition of Oxyrrhis marina. Journal of the Marine Biological Association of the United Kingdom 1959, 38:605-620.

26. Lowe CD, Day A, Kemp SJ, Montagnes DJS: There are high levels of functional and genetic diversity in Oxyrrhis marina. The Journal of Eukaryotic Microbiology 2005, 52:250-7.
27. Lowe CD, Martin LE, Roberts EC, Watts PC, Wootton EC, Montagnes DJS: Collection, isolation and culturing strategies for Oxyrrhis marina. Journal of Plankton Research 2011, 33:569-578.

28. Altschul SF, Gish W, Miller W, Myers EW, Lipman DJ: Basic Local Alignment Search Tool. Journal of Molecular Biology 1990, 215:403-410.

29. Conesa A, Götz S, García-Gómez JM, Terol J, Talón M, Robles M: Blast2GO: a universal tool for annotation, visualization and analysis in functional genomics research. Bioinformatics 2005, 21:3674-6.

30. The Gene Ontology Consortium: The Gene Ontology in 2010: extensions and refinements. Nucleic Acids Research 2010, 38:D331-5.

31. Huang X, Madan A: CAP3: A DNA Sequence Assembly Program. Genome Research 1999, 9:868-877.

32. Zhang Z, Li J, Zhao X-Q, Wang J, Wong GK, Yu J: KaKs_Calculator: calculating $\mathrm{Ka}$ and $\mathrm{Ks}$ through model selection and model averaging. Genomics, Proteomics \& Bioinformatics 2006, 4:259-63.

33. Romualdi C, Bortoluzzi S, D'Alessi F, Danieli GA: IDEG6: a web tool for detection of differentially expressed genes in multiple tag sampling experiments. Physiological Genomics 2003, 12:159-62.

34. Pfaffl MW: A new mathematical model for relative quantification in realtime RT-PCR. Nucleic Acids Research 2001, 29:e45.

35. Marygold SJ, Roote J, Reuter G, Lambertsson A, Ashburner M, Millburn GH, Harrison PM, Yu Z, Kenmochi N, Kaufman TC, Leevers SJ, Cook KR: The ribosomal protein genes and Minute loci of Drosophila melanogaster. Genome Biology 2007, 8:R216.

36. Kanehisa M, Goto S, Kawashima S, Okuno Y, Hattori M: The KEGG resource for deciphering the genome. Nucleic Acids Research 2004, 32:D277-80.

37. Joseph SJ, Fernández-Robledo JA, Gardner MJ, El-Sayed NM, Kuo CH, Schott EJ, Wang H, Kissinger JC, Vasta GR: The Alveolate Perkinsus marinus: biological insights from EST gene discovery. BMC Genomics 2010, 11:228

38. Reichman JR, Wilcox TP, Vize PD: PCP gene family in Symbiodinium from Hippopus hippopus: low levels of concerted evolution, isoform diversity, and spectral tuning of chromophores. Molecular Biology and Evolution 2003, 20:2143-54.

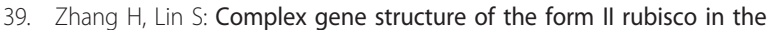
dinoflagellate Prorocentrum minimum (Dinophyceae). Journal of Phycology 2003, 39:1160-1171.

40. Bertomeu T, Morse D: Isolation of a dinoflagellate mitotic cyclin by functional complementation in yeast. Biochemical and Biophysical Research Communications 2004, 323:1172-83.

41. Ginder ND, Binkowski DJ, Fromm HJ, Honzatko RB: Nucleotide complexes of Escherichia coli phosphoribosylaminoimidazole succinocarboxamide synthetase. The Journal of Biological Chemistry 2006, 281:20680-8.

42. Hartz AJ, Sherr BF, Sherr EB: Photoresponse in the heterotrophic marine dinoflagellate Oxyrrhis marina. The Journal of Eukaryotic Microbiology 2011, 58:171-7.

43. Lowe CD, Montagnes DJS, Martin LE, Watts PC: High genetic diversity and fine-scale spatial structure in the marine flagellate Oxyrrhis marina (Dinophyceae) uncovered by microsatellite loci. PLOS ONE 2010, 5:e15557.

44. Droop MR, Pennock JF: Terpenoid quinones and steroids in the nutrition of Oxyrrhis marina. Journal of the Marine Biological Association of the United Kingdom 1971, 51:455-470.

45. Hall RP: Nutrition and growth of protozoa. In research in protozoology.. 1 edition. Edited by: TT C. Oxford: Pergamon Press Ltd; 1967:337-404.

46. Droop MR: Nutritional investigation of phagotrophic protozoa under axenic conditions. Helgoland Marine Research 1970, 277:272-277.

47. Hou Y, Lin S: Distinct gene number-genome size relationships for eukaryotes and non-eukaryotes: gene content estimation for dinoflagellate genomes. PLOS ONE 2009, 4:e6978.

48. Yang I, John U, Beszteri S, Glöckner G, Krock B, Goesmann A, Cembella AD: Comparative gene expression in toxic versus non-toxic strains of the marine dinoflagellate Alexandrium minutum. BMC Genomics 2010, 11:248

49. Toulza E, Shin M-S, Blanc G, Audic S, Laabir M, Collos Y, Claverie JM, Grzebyk D: Gene expression in proliferating cells of the dinoflagellate Alexandrium catenella (Dinophyceae). Applied and Environmental Microbiology 2010, 6.

50. Bai X, Adams BJ, Ciche TA, Clifton S, Gaugler R, Hogenhout SA, Spieth J, Sternberg PW, Wilson RK, Grewal PS: Transcriptomic analysis of the entomopathogenic nematode Heterorhabditis bacteriophora TTO1. BMC Genomics 2009, 10:205 
51. Maheswari U, Mock T, Armbrust EV, Bowler C: Update of the diatom EST database: a new tool for digital transcriptomics. Nucleic acids research 2009, 37:D1001-5.

52. Wang Z, Gerstein M, Snyder M: RNA-Seq: a revolutionary tool for transcriptomics. Nature Reviews Genetics 2009, 10:57-63.

53. Marioni JC, Mason CE, Mane SM, Stephens M, Gilad Y: RNA-seq: an assessment of technical reproducibility and comparison with gene expression arrays. Genome Research 2008, 18:1509-17.

54. Wall PK, Leebens-Mack J, Chanderbali AS, Barakat A, Wolcott E, Liang H, Landherr L, Tomsho LP, Hu Y, Carlson JE, Ma H, Schuster SC, Soltis DE, Soltis PS, Altman N, DePamphilis CW: Comparison of next generation sequencing technologies for transcriptome characterization. BMC Genomics 2009, 10:347.

55. Torres T, Metta M, Ottenwälder B, Schlötterer C: Gene expression profiling by massively parallel sequencing. Genome Research 2008, 1:172-177.

56. Duftner N, Larkins-Ford J, Legendre M, Hofmann HA: Efficacy of RNA amplification is dependent on sequence characteristics: implications for gene expression profiling using a cDNA microarray. Genomics 2008, 91:108-17.

57. Mcneil SD, Nuccio ML, Ziemak MJ, Hanson AD: Enhanced synthesis of choline and glycine betaine in transgenic tobacco plants that overexpress phosphoethanolamine $\mathrm{N}$-methyltransferase. Proc Natl Acad Sci USA 2001, 98:10001-10005.

doi:10.1186/1471-2164-12-519

Cite this article as: Lowe et al:: The transcriptome of the novel dinoflagellate Oxyrrhis marina (Alveolata: Dinophyceae): response to salinity examined by 454 sequencing. BMC Genomics 2011 12:519.

\section{Submit your next manuscript to BioMed Central} and take full advantage of:

- Convenient online submission

- Thorough peer review

- No space constraints or color figure charges

- Immediate publication on acceptance

- Inclusion in PubMed, CAS, Scopus and Google Scholar

- Research which is freely available for redistribution

Submit your manuscript at www.biomedcentral.com/submit
( Biomed Central 